\title{
The impact of PTSD on veterans' family relationships: An interpretative phenomenological inquiry
}

\author{
Susan L. Ray ${ }^{\mathrm{a}, *}$, Meredith Vanstone ${ }^{\mathrm{b}}$ \\ a The University of Western Ontario, Faculty of Health Sciences, School of Nursing, HSA \#32, London, Ontario, Canada N6A 5C1 \\ ${ }^{\mathrm{b}}$ Health and Rehabilitation Sciences, Faculty of Health Sciences, The University of Western Ontario, London, Ontario, Canada N6A $5 \mathrm{C} 1$
}

\begin{abstract}
A B S T R A C T
Background: Although there is a significant amount of literature on veterans with PTSD, there is a limited amount of literature on the impact of PTSD on veterans' family relationships and in turn, how these relationships impact healing from trauma. There is evidence that supportive families and friends are immensely helpful to those recovering from PTSD, but how do the symptoms of PTSD impact family relationships and in turn, impact healing from trauma?

Objectives: This paper examines the impact of PTSD on veterans' family relationships and the impact of these relationships on healing from trauma.

Design: This is a secondary analysis of a currently unpublished study on contemporary peacekeepers healing from trauma. An interpretative phenomenological approach was used as the methodological framework for the study.

Settings: Peacekeepers were recruited from Ontario, although they originated from all over Canada and had experienced active service in many different international locations. Participants: Ten contemporary peacekeepers aged 37-46 who had been deployed to Somalia, Rwanda or the former Yugoslavia were interviewed. The peacekeepers had a variety of ranks, specializations, experience, and service records. Each peacekeeper had been receiving treatment for PTSD for at least 2 years.

Methods: Data analysis followed the phenomenological method which seeks to uncover the meanings of phenomena experienced by individuals through the analysis of their descriptions. As the themes evolved for the secondary analysis, the primary researcher returned to the transcripts several times for verification of meaning and to find exemplary quotes.

Results: Two major themes emerged on the impact of PTSD on veterans' family relationships and how these relationships impact healing from trauma: emotional numbing and anger negatively impacts familial relationships; and emotional withdrawal from family support creates a struggle with healing from trauma.

Conclusion: The impact of PTSD on veterans' family relationships, in particular the symptoms of emotional numbing and anger should be heeded. It is recommended that treatment for PTSD include support of the family and interpersonal skills training for military personnel suffering while healing from trauma. Future studies are needed to further explore the impact of PTSD on veterans' family relationships in order to provide the best treatment approaches.
\end{abstract}


What is already known about the topic?

- Social support is strongly correlated to positive treatment outcomes among individuals with PTSD. A lack of social support is strongly correlated to negative PTSD treatment outcomes.

- Emotional numbing and anger are two of the main symptoms of PTSD. It is a group of symptoms that manifests in problems experiencing and expressing emotion.

- PTSD impacts not only the veteran who has the diagnosis, but his/her close family members as well.

What this paper adds

- A qualitative study on the impact of PTSD on veterans' family relationships and the impact of these relationships on veterans healing from trauma.

- Emotional numbing and anger by the veteran can push family members away. The withdrawal of support from family members can result in increased manifestation of symptoms such as emotional numbing/avoidance and anger which creates a struggle with healing from trauma.

- Disruption in the family relationship causes great psychological turmoil to veterans healing from PTSD. Practitioners are recommended to include strategies to support families and to include interpersonal skills training for military personnel suffering while healing from trauma.

\section{Introduction}

Throughout history, nursing has had strong roots in the health care of soldiers who have served in war and peacetime deployments. In the peacekeeping missions of the 1990s, peacekeepers found themselves in highly uncertain, complex and ambiguous environments with a tangle of self-proclaimed authorities-militias, warlords, and other armed groups (Dallaire, 2003). The violence of these intrastate wars has left a lasting psychological impact on contemporary peacekeepers (Dallaire, 2003: English, 1999; Passey and Crockett, 1999). Although there is a significant amount of literature on veterans with Posttraumatic Stress Disorder (PTSD), there is little written on the impact of PTSD on veterans' family relationships and the impact of these relationships on healing from trauma. In light of the present deployments of multinational troops to countries worldwide, it is vital that nurses, other health care professionals and policy makers understand the impact of PTSD on family relationships to order to provide the best treatment to veterans healing from PTSD.

\section{Background}

Numerous quantitative studies have demonstrated that PTSD effects not only the veteran who has received the diagnosis, but several domains of family functioning including family cohesion, parenting satisfaction, relationship with spouse, self-identity of spouse, functioning and emotional security of children (Gavlovski and Lyons, 2004; King et al., 2006). Poor functioning in these domains has been correlated to higher rates of divorce and higher occurrences of clinically significant levels of relationship distress in the families of veterans with PTSD than in the families of veterans without PTSD or in the general population (Gavlovski and Lyons, 2004; King et al. 2006). Veterans with PTSD are more likely than members of the general population to have clinically significant levels of depression, anxiety, anger, and violence. They are more likely to abuse substances and less likely to hold steady employment (Kessler, 2000; Taft et al., 2005).

The family environment impacts the health of all the members of the family unit. Repetti et al. (2002) found that poor health outcomes for children (including depression, poor development, higher rates of illness, lower academic performance, cardiovascular and neuroendocrine disruption) were closely linked to a stressful family environment. Many of the traits of a stressful family environment as defined by Repetti et al. (2002) are common symptoms of PTSD and emotional numbing. The common traits of a stressful family environment and PTSD include high levels of marital conflict, cold and unresponsive parenting style, social isolation, anger, absence of emotional warmth and responsiveness, parental depression, lack of support and low family cohesiveness (Kessler, 2000).

It is not just children and spouses that are negatively affected by the symptoms of PTSD. The symptoms of PTSD make it difficult for veterans to maintain strong family relationships which complicates the situation as social support (in the form of a positive home coming reception, strong family relationships and strong social networks) minimizes the impact and severity of PTSD symptoms and improves treatment outcomes (Bolton et al., 2002; Koenen et al., 2003; Ruscio et al., 2002).

Veterans who face conflict at home have much poorer treatment outcomes (Gavlovski and Lyons, 2004; King et al., 2006). This leaves veterans with PTSD in a difficult situation: treatment outcomes are much improved by strong social relationships, but they are unlikely to have high levels of social support. The symptoms of PTSD contribute to a stressful and dysfunctional family environment which decreases familial support in the healing process and delays the return of positive interpersonal behaviour.

There is significant literature that investigates emotional numbing, one of the primary symptoms of PTSD, and its relationship on family functioning. Emotional numbing is listed as one of the main symptoms of PTSD in the American Psychiatric Association's DSM IV (APA, 2000). Emotional numbing is defined as a cluster of symptoms that manifests in a "markedly diminished interest in significant activities, feelings of detachment or estrangement from others and a restricted range of affect" (APA, 2000). King et al. (2006), Rosenheck and Thomson (1986) and Ruscio et al. (2002) have made a beginning link that emotional numbing, other PTSD symptoms and low levels of social support have a negative effect on familial relations.

Most of the work in this area is quantitative and relies on standardized measures to assess multi faceted topics such as social support networks, parenting satisfaction, marital satisfaction, and family cohesion and treatment 
outcomes. There are a few qualitative studies investigating the experience of being a family member of a veteran with PTSD (Dekel et al., 2005; Frederikson et al., 1996). However, there are no qualitative studies on veterans' views of the impact of PTSD on family relationships and the impact of these relationships on veterans healing from trauma.

\section{Aim}

The data presented here are part of a larger interpretative phenomenological study (Ray, in press) titled: The experience of contemporary peacekeepers healing from trauma. However, many years after their deployments and treatment, the peacekeepers were still trying to heal from trauma. Thus, their struggle with healing became a focus throughout the primary study into healing from trauma. The aim of the secondary analysis of the data was to deepen our understanding of the impact of PTSD on family relationships and how these relationships impact healing from trauma.

\section{Design}

An interpretative phenomenological approach as articulated by Merleau-Ponty (1962) and Van Manen (1998a) was used as the methodological framework for the study. Interpretative phenomenology is a methodology used when the research question asks for meanings of a phenomenon with the purpose of understanding the human experience. Interpretive phenomenology is committed to an inter-subjective understanding of the body which is historically situated, and relational, and defined by Merleau-Ponty (1962) as a "being-to-the-world". According to Merleau-Ponty (1962) phenomenology is a methodology of describing the nature of our perceptual contact with the world. All experience is perceptual and perception integrates mind, body, world and time. Merleau-Ponty (1962) helps us to understand that embodiment is essential to life situations where the presence of the body gives these other life existentials their meaning, i.e. time, space and relation. The "intentional arc" is a central concept in Merleau-Ponty's philosophy of embodiment which connects these existential life-world themes that help us to make sense of life in time and space-past, present, and future (Wilde, 1999). Such a term suggests human knowledge is relational, temporal, and present in the world, as opposed to being objective, static, and independent of the questioner. By viewing the human subject as embodied and the body as a body-subject, healing from trauma is understood as a composite and complex whole that is experienced in the world in a concrete way. These four existential life-world themes probably pervade the life worlds of all human beings, regardless of their social, historical, or cultural situatedness (Van Manen, 1998a). Thus, the research was guided by reflection upon lived body (corporeality); lived space (spatiality); lived human relation (relationality or communality; and lived time (temporality) that van Manen interprets as Merleau-Ponty's life-world existentials of experience.

\section{Participants}

For the primary study, potential participants were invited to participate in the study via a letter of invitation sent to the Coordinator of the Operational Stress Injury Social Support (OSISS) who distributed the letter to potential participants. OSISS is a national peer support network for Canadian Forces members, veterans and their families. The letter of invitation included relevant information pertaining to the study and a contact number to reach the researcher if they were interested in participation. Throughout the study, contemporary peacekeeper participants were selected on the basis of the following: (1) Participants had been deployed to Somalia, Rwanda or the former Yugoslavia. These deployments were chosen because they are reflective of the changing landscape experienced by contemporary peacekeepers. All of these deployments represent intrastate conflict (civil wars) which have erupted since the collapse of the Berlin Wall. (2) Participants had received treatment a minimum of 2 years for PTSD following their deployments. (3) Participants were in recovery from trauma a minimum of 2 years. It was important to interview peacekeepers who had received treatment for 2 years and who were in recovery a minimum of 2 years in order to explore their experience of healing from trauma. In my clinical experience, a minimum of 2 years is necessary in order for any healing to occur from the trauma of peacekeeping. (4) Participants were able to speak and read the English language at a Grade 8 level. (5) Participants had the reflective capacity to recall their experiences of healing from trauma, and a willingness to share these experiences with the researcher.

Exclusion criteria included: Under 18 years of age, cognitively impaired, residing in institutions (e.g. prison, extended care facility), students, employees of the researcher's organization, in emergency or life-threatening situations, language barriers (e.g. illiterate, not Englishspeaking, dysphasic) and living outside of South Western Ontario. In addition, the researcher did not interview any peacekeepers that I had worked with as a therapist. Therefore, of the 16 potential participants that contacted the researcher, a purposive sample of 10 contemporary peacekeepers aged 37-46 who met the criteria were chosen to participate. The 10 participants included 6 soldiers (Luke, Simon, Peter, James, John and Tim), 2 chaplains (Thomas and Matt), 1 medical assistant (Paul) and 1 female nurse (Mary). Their names were changed to pseudonyms for the purpose of anonymity and written consents were obtained from the participants.

\section{Data collection and analysis}

In the primary study, data was collected in 2005 via one tape-recorded, in-depth interview with each of the 10 peacekeepers. The research questions used in the interview were: What was the experience of contemporary peacekeeping and how did it lead to trauma? What is the experience of healing from the trauma of peacekeeping? Are contemporary ways of treatment helping you to heal? The aim of the secondary analysis was to address the research questions: What is the impact of PTSD on veterans' family 
relationships; and what is the impact of these relationships on healing from trauma? The interviewing style used in the original study enhanced the richness of the data available to address the research questions for the secondary analysis. The interviews were not constrained by only answering a rigid set of questions; instead, they were allowed to emphasize what was important to them in their experience. Thus, the peacekeepers were able to give rich descriptions of their experience of healing from trauma which shed some light on the impact of PTSD on veterans' family relationships and in turn, the impact of these relationships on healing from trauma.

Verbatim transcriptions were interpreted and reflective journaling by the primary researcher provided further clarification of pre-understanding and further understanding of the impact of PTSD on family relationships and the impact of these relationships on healing from trauma. The goal of this dialogue was the intersection of the horizon of the participant and the horizon of the primary researcher with a view to more deeply understand the participants' experiences.

The reflective journal reinforced rigor within the study, insofar as I was made aware of my personal biases and unique perspective that I brought to the research project. I have been working for 25 years in mental health nursing with civilian populations suffering from various forms of trauma and the last 3 years as a Clinical Nurse Specialist in an outpatient clinic for enlisted and veterans who have been traumatized from their military experiences. In my experience, diagnostic labels and stage models of healing or recovery are representations that fail to grasp the totality of the being before us. I believe that nurses and other health care professionals need to understand not only symptomatic responses but the experience of contemporary peacekeeping healing from trauma. The significance of the secondary analysis rests with the opportunity to provide a richer and deeper understanding of the impact of PTSD on veterans' family relationships and the impact of these relationships on healing from trauma.

\section{Methods}

Although all 10 transcripts from the primary study were selected, 7 were chosen for secondary data analysis because these participants spoke extensively about the impact of PTSD on their families. Data analysis followed the phenomenological method which seeks to uncover the meanings of phenomena experienced by individuals through the analysis of their descriptions. Van Manen (1998a) offers six interactive approaches for interpretative phenomenological inquiry and analysis of the data: Orienting oneself to the phenomenon of interest and explicating assumptions and pre-understandings; investigating experiences as lived through conversational interviews rather than as we conceptualize it; reflecting upon and conducting thematic analysis which characterize the phenomenon and interpreting through conversations; describing the phenomenon through the art of writing and re-writing (re-thinking, re-flecting, re-cognizing) which aims at creating depthful writing; main- taining a strong and oriented relation to the fundamental question about the phenomenon; and balancing the research context by considering parts and wholes. These six practical interactive approaches acted as a guide towards understanding the impact of PTSD on family relationships and the impact of these relationships on healing from trauma.

This type of secondary analysis of qualitative research has been described as 'analytic expansion' in which the researcher conducts a secondary interpretation in order to put new questions to the primary material that was originally collected for different research questions (Heaton, 2004; Thorne, 1998). The inability to strictly follow the guidelines of the chosen method for secondary analysis is a limitation. Van Manen's method in particular the third step which involves "interpreting through conversations" by returning to the participants could not be followed. In secondary analysis, it is appropriate to obtain interpretation validation by another person such as the secondary researcher (Szabo and Strang, 1997). Verification of meaning was ensured by having the primary researcher confirm with the secondary researcher the core themes found in the data. As the themes evolved, the primary researcher returned to the transcripts several times for verification of meaning and to find exemplary quotes.

\section{Ethical considerations}

Ethics approval for the primary study and the secondary analysis was obtained from the appropriate university review board. Participants were assured that data would be kept confidential and only the research team would have access to identifying information. The meaning of a secondary analysis was explained to each participant. Oral and written consents were obtained which included an agreement that there would be a secondary analysis of the data.

\section{Findings}

The essence of the phenomena of the impact of PTSD on family relationships and the impact of these relationships on healing from trauma as revealed from the secondary analysis of the text was one of emotional numbing/ avoidance and anger affecting familial relationships negatively with an intensified cycle of emotional withdrawal and retreat for both the veterans and their families creating a struggle with healing from trauma. Two major themes emerged from the text on the impact of PTSD on family relationships and the impact of these relationships on healing from trauma. The first theme illustrates how emotional numbing can negatively impact familial relationships and cause further emotional withdrawal. This theme is one half of the cycle of emotional pain. The second half of the cycle is expressed in the second theme; emotional withdrawal from family support creates a struggle with healing from trauma. Each theme with supporting verbatim descriptive excerpts from the peacekeepers is presented below followed by an interpretation based on the life-world existentials. 
10. Theme: emotional numbing/avoidance and anger negatively impacts familial relationships

\section{Timothy...}

I started isolating and dissociating at home. After Somalia, my wife and I went through a period of arguments. She asked me to seek help. I said I don't need help. She goes to see the psychologist because she doesn't like the way I am. I'm more protective of my one year old daughter and son after seeing all these dead children. I am holding his hand and cuddling him. I walked about 10 feet away from him taking back a grocery cart, watch for traffic. . .l'm the body guard.

Thomas. . .

I've seen how PTSD affected my wife and kids. My wife can understand it at one level but still I am not doing anything. Why don't I go out? It really had a profound effect on my oldest son because when I shut down then the relationship with him changed. He has a lot of anger and hurt. He was basically abandoned. . unable to understand why I have these mood swings and anger. It changed the family dynamic, around him. My interaction with the psychiatrist revolved around how my wife, my other son and the youngest two are dealing with my oldest son and his treatment.

Paul...

I was more anxious... stressed; I had a lot more anger. I was making my family and my kids suffer with some physical and psychological abuse. I was still closed up in what I was saying or doing. I was trying to find the answers in my head as to why I'm like that and what's happening with me. My wife said... you've changed, you're different. I said no. Three times my marriage almost broke up. Part of it is a couple, but a big part was me. I never realized that they were symptoms of PTSD but now I know that was the reason.

James...

I was isolating myself and ignored my family life. The priority was my feelings not my daughter and my girlfriend. What happened was an unhealthy relationship. My ex girlfriend was able to press that button again and tell my daughter that her dad was an ass hole. I snapped. . grabbed some of her hair. The next thing... had a loaded rifle in my hand... would have done it straight away, I was hurting that badly. I would not want to traumatize my daughter, so I threw the rifle in my truck. As soon as I left the house it was almost like it was gone, and reality kicked back in. I'm thinking. .. what am I doing? Like flipping a switch and I was totally calm. All this rage I had was gone. I was charged with assault. . given two years probation, a suspended sentence with an order to take anger management.

Simon...

If I continue to change. . how am I going to be a father? How am I going to stay alone with my kids? I have no resilience. . .can't deal with stress. I'm always angry. I don't want to see anybody. PTSD erodes all of your normal emotions. . .a whole range of emotions were eradicated through this illness. I think this is the biggest change. I'm left with three emotions: mad, sad, and glad. There's a huge difference between being capable of being happy because your son did well in school, and being simply glad about it. I don't know what happy is any more. I find that to live nowadays a quasinormal life, I need to hide getting triggered because I don't want to scare my kids and my wife. They need to live their lives not worrying about this crap all the time.

Luke...

I suppressed...pushed down all of it...thought I would probably get over it in time. It brought to me how important the truth was, in that I could no longer call home and tell my son that daddy was all right. . doing okay. I remember my brother looking at me and saying "What the heck is going on?" What I was doing wasn't just affecting me; it was affecting others around me.

Merleau-Ponty (1962) helps us to understand that embodiment is essential to life situations where the presence of the body gives the other life existentials their meaning, i.e. time, space and relation. The experience of our bodies is an interpersonal or relational experience. Merleau-Ponty (1962) conceptualized the embodied person existing in a knot of relationships that opens a person to the world. He described the body as catching, comprehending, and spontaneously responding to the communications of another person.

Perceptions fill the core of our persons and gradually define our world, taking possession of our being and totally permeating it as understanding speaks through the body (Merleau-Ponty, 1962). Yet peacekeepers find their perceptions of their world profoundly disturbed upon their return home which impacts their lived relations or the 'knot of relations' in lived space and lived time in negative ways. Timothy found that 'isolating and dissociating at home' strained his relationship with his wife. Thomas found that his wife had a hard time dealing with the practical implications of PTSD. With several children, she wanted her husband to be an active parent. Thomas 'shut down' and withdrew from the family which increased the burden of parental duties upon his wife. Paul found that he was 'closed up' which at times resulted in angry and sometimes violent outbursts. This behaviour led to marital instability and very nearly led to divorce. James had a similar experience to Thomas. Upon his return from overseas, 'isolating' himself placed significant strain on his relationship with his girlfriend and daughter, ultimately, this lead to a confrontation and a violent outburst. His dissociative reaction was like 'flipping a switch'. Simon found that PTSD left him with only three emotions 'mad, sad, and glad'. In particular, like most veterans, Simon found that anger was one of the only emotions experienced. Just as Simon's children realized that there was something going on with him, so did Luke's family. Luke worked to 'suppress' his emotions so that he could continue on and lead a normal life when he returned home. He eventually realized that this suppression of emotions or emotional numbness was affecting his 
children and other family members by preventing him from being an active father, husband, and brother.

As illustrated in the excerpts, trauma is profoundly disruptive to the life-world existentials. Alterations in perception affects the peacekeepers embodied experience in lived time, lived space and lived relations. Based on the work and the approach of phenomenological philosophers, most notably Merleau-Ponty, Beere (1995) presented a perception based theory of dissociation, and defined the "perceptual background" as the experiential context for all perceptual experience. All experience is perceptual and perception integrates the life-world existentials of body, time, space and relations. The perceptual background establishes and reveals the contextual meaning for experience and is always present during non-dissociated, everyday experience (Beere, 1995). Beere hypothesized that specific dissociative symptoms originate from the loss of or change in the perceptual background because there is a focused perception during trauma on what is frightening. The source of the threat will engage perception, shifting it away from non-threatening background components. Peacekeepers suffering from trauma have alterations in perception focused on traumatic experiences overseas while bodily living at home. Therefore, the peacekeepers either react with dissociative symptoms such as emotional numbing/avoidance or anger associated with hyper arousal/hyper vigilance or being on guard.

Traumatized persons may try to distance the emotional component of a traumatic memory by a type of dissociative reaction called "depersonalization". Depersonalization can appear as taking an objective, third person perspective 'from the balcony', in order to remove unacceptable emotions from your perspective which may be experienced as a sense of emotional numbness (Beere, 1995). This is sometimes called "dissociation of affect" or emotional detachment from the lived body. Dissociating from the painful emotion includes "numbing out" all emotion, and the person may seem emotionally flat, preoccupied or distant. The peacekeepers are unable to either express or feel any emotion or are limited to anger and sadness. These same alterations in perception that enabled the peacekeepers to survive the trauma become obstacles at home. Because of alterations in perception experienced by the peacekeepers, their emotional numbing/avoidance and anger negatively impacted their familial relationships.

11. Theme: emotional withdrawal from family support creates a struggle with healing from trauma

Peter...

You have to have feelings in order to have friends and relationships otherwise you're going to be very lonely and lead a very lonely life. You have to learn how to be a person again and rebuild who you were, and be able to function in that family unit. My wife would like to be able to walk down the street, hold hands, and snuggle...the intimacy thing. Even after two years of couple's therapy. . . I still feel very much alone.
Luke...

I don't think my wife or my son totally understood what it was like to be me. My son has certain behavioural problems that were supported by his mother. I could no longer live in a less than supportive home environment of chaos and confrontation. There are parallels for a PTSD kind of guy, whether he's in a tank or at work or in a confrontational home environment. I've rescued myself by separating myself from my family. Since I have left she has now seen some of those things that I've been trying to communicate all those years.

Simon...

My wife mentioned that she misses the decisiveness and hopes I could be like I used to be. She liked me being in control, I'd say let's go out tonight. Now I don't really like to go out. I couldn't make a decision on where the hell we're going to go if my life depended on it. I can't deal with disappointment... never wanted to disappoint anybody. There are no emotional attachments. If something goes wrong, I don't want to be the cause. . don't want to be the troublemaker. The safe thing is not to do anything. You isolate yourself. You just don't want to take that risk. I can't deal with family crisis any more. It's like a paralysis.

The world is experienced through our body and it is a sensual and emotive experience. It is not an emotional discourse in the sense of what I am feeling but an intimate discourse in terms of how emotions are shared and interpreted by others (Crossley, 1995). Van Manen (1998a) suggests that "lived other" (relationality) is the lived relation we maintain with others in the interpersonal space or lived "felt space" (spatiality) that we become and share with them" (p. 104). The lived interpersonal space is measured by the space of activity of human associations (Bollnow, 1961). Merleau-Ponty (1962) describes this as a process of 'inter-corporeality', where emotions are both worldly and material in form. This 'inter-corporeality' is constituted by our bodily techniques that manifest our intentions and feelings (Crossley, 1995, p. 146). Emotions can be understood as "embodied, as inseparable from bodily practices such as gestures, rooted in the intimacy and immediacy of instantiated or corporeal interchange: face-to-face, body-to-body" (Crossley, 1995, p. 145).

Lived time, lived space and lived relations are directly experienced and embodied, and are interwoven with emotion and affective states of perception (Crossley, 1995). Emotions are ways of being in the world; that is, ways of making sense of and acting in the world. Emotional states entail perceiving the world in particular ways and noticing and being affected by things that one might not usually be affected by.

The continued alteration in their emotional and affective states of perception profoundly affects the peacekeepers lived relations with their family and friends back home. Peter noticed that after his return from combat, he withdrew from social situations and lost many friendships. He recognizes that his relationship with his wife deteriorated because of his emotional numbing. He thinks that he has trouble with emotional relationships because he has a hard 
time experiencing emotions or feelings other than anger and sadness. This has created a struggle with healing from trauma because Peter realizes 'you have to have feelings' to have friends and an intimate relationship with his wife. Luke's family withdrew their support as they had a hard time dealing with the loss of the father, husband and brother they remembered. When Luke could not resume his former role in the family, there was a lot of conflict, which negatively impacted his PTSD symptoms and caused more conflict, creating a vicious circle which created a struggle with healing from trauma. 'By separating myself from my family', Luke continues to struggle with healing from trauma as the "lived other" (relationality) or 'inter-corporeality' with his family is missing. Some veterans like Simon see their emotional numbing as protective of family members. They don't want to share their experiences or let their family members see them as psychologically vulnerable in order to protect their family members. Simon is so worried about upsetting his wife and children; he makes 'no emotional attachments' thereby, compounding his struggle with healing from trauma. Our bodily memories are needed to fill us with feelings and to prove that we exist. Bodily feelings and emotions are needed in order to experience the intimacy of both corporeal and 'inter-corporeal' interchange (Crossley, 1995). Thus, the continued inability to feel embodied emotions and feelings detaches and further distances the peacekeepers from their relationships with friends and family.

According to Merleau-Ponty (1962), lived time (temporality) is subjective time as opposed to clock (objective) time. In the above excerpts, we see the subjective experience of lived space and lived time perceptions change and become out of sync with objective time and space. Experiences of trauma become freeze-framed into an eternal present in which one remains forever trapped, and all duration or stretching along collapses, past becomes present and future loses all meaning other than endless repetition (Stolorow, 2003). The peacekeepers perception of time as frozen is protective during their traumatic experience while overseas. Upon their return home, the past overseas has become the present where they feel and react as if all or part of themselves stayed over there. Tim responds to his children as reminders of 'seeing all these dead children'. Luke responds the same 'whether he's in a tank' or at home. The alteration of lived time upon their return home leads to continued suffering and difficulty with family relationships as it removes the participants from living life in the present. In this sense, it is trauma and suffering from the trauma that is timeless. Because trauma so profoundly alters the universal or shared structure of temporality, the traumatized person, quite literally, lives in another kind of reality; an experiential world incommensurable with those of others (Stolorow, 2003). This felt incommensurability, in turn, contributes to the sense of alienation and estrangement from other human beings that typically haunts the traumatized person. Torn from the communal fabric of being-in-time, trauma remains insulated from human dialogue (Stolorow et al., 2002).

Upon their return home, the disruption in the unifying thread of temporality accompanied by their inability to feel embodied emotions and feelings detaches many peacekeepers from their current life experiences. Thus, emotional withdrawal from family often causes the withdrawal of family social support which in turn, creates a struggle with healing from trauma.

In conclusion, the problematic area of embodiment is so often overlooked or minimized in discussions of trauma (Young, 1992). The aftermath of trauma i.e. dissociation from the body and emotional numbing have a great deal to do with living comfortably (or not) in the human body (Young, 1992). Veterans wall off the traumatic memories and emotions stored in their bodies. This gives survivors some measure of control over painful past events (Timms and Connors, 1992; Levine, 1997; Young, 1992). However, such a solution entails an enormous sacrifice, since it also makes problematic experiencing the everyday pleasures, sensations, and emotions of human embodiment and prevents meaningful relationships with others (Young, 1992).

\section{Discussion}

Over $70 \%$ of spousal relationships of Vietnam veterans with PTSD experienced clinically significant levels of relationship stress as compared to $30 \%$ without PTSD (Riggs et al., 1998). Riggs et al. (1998) and Samper et al. (2004) recognized the effect that emotional numbing (for instance, loss of interest in activities, detachment from others, restricted effect) and the symptoms of hyper arousal (irritability and concentration problems) have on many important aspects of the spousal relationship such as pair bonding activities and conflict resolution strategies. Dekel et al. (2005) found that nine partners of Israeli veterans with PTSD reported feelings of tension, somatic complaints, anxiety, depression, low self-esteem, loneliness, confusion, self-blame, and loss of control. They talked about how the illness of their partner shaped their physical and emotional lives, even influencing their behaviour outside the home. The wives struggled to maintain control of their personal space and family while dealing with a partner who was physically there but psychologically absent. Contrary to the high divorce rates among Vietnam veterans with PTSD, Dekel et al. (2005) found that these wives had a strong commitment to their husband and often saw separation or divorce as an impossible path. This finding was supported in the present study as only one of the peacekeepers had experienced a separation and divorce.

Emotional numbing and anger is also highly correlated to woman abuse (both physical and psychological) in couples with PTSD (Gavlovski and Lyons, 2004). Veterans with PTSD are more likely to be perpetrators of domestic violence than veterans without PTSD (Taft et al., 2007). The presence of PTSD, not combat exposure, is the factor associated with elevated levels of violence. Partners of veterans with PTSD consistently exhibit higher rates of psychological problems and lower rates of psychological adjustment with symptom severity at clinical levels than partners of veterans without PTSD (Manguno-Mire et al., 2007). Frederikson et al. (1996) found that fear of spousal anger and violence was a common theme in the everyday 
experiences of women living with spouses who suffered from PTSD. However, Williams (1980) noted a pattern of a small number of extremely violent episodes that led to treatment seeking. The current study supported this finding as James was the only peacekeeper who assaulted his girlfriend and consequently was forced to seek treatment for his anger. Whether or not anger leads to physical violence, it damages emotional relationships with family members and is a significant part of the cluster of emotional numbing symptoms.

Emotional numbing and anger can also significantly impact the veteran's relationship with his children. (Samper et al., 2004; Ruscio et al., 2002) have hypothesized that the veteran's feelings of detachment from the world carry over into his relationship with his children. Although they found correlations between relationship quality and re-experiencing, effortful avoidance, and hyper arousal, the correlation with emotional numbing with low parenting satisfaction and poor parent-child relationship quality was much stronger than that of any of the other PTSD symptoms. Samper et al. (2004) make the conjecture that this detachment between parent and child may cause children to act out, further affecting the relationship and the parent's satisfaction. Thomas experienced this with his family. Prior to his service, he had a special relationship with his eldest child, who had behavioural difficulties. The special relationship between Thomas and his son helped ameliorate some of the son's behavioural problems. When Thomas started suffering from PTSD and withdrew from that relationship, his son started acting out more and eventually Thomas and his wife decided it would be best for everyone if the son moved into a residential treatment facility. Timothy noticed that after 2 years of treatment and medication, his PTSD symptoms became less pronounced and his relationship with his children started to improve.

Curran (1997) noted that one of the ways that PTSD can affect the father-child relationship is that fathers can become preoccupied with the safety of their children. They may feel as if they need to be constantly on guard to protect their children from any number of unseen dangers. Although, there was no significant exploration of this issue in the literature, it was certainly present in this study. Timothy described feeling like a "body guard" for his children. There was evidence in the data that some veterans may see their emotional numbing and avoidance as protective of their family. By not discussing their feelings or experiences, they see themselves protecting their children, spouse, and loved ones. However, veterans who are experiencing emotional numbing, avoidance, and anger are not modelling good behaviour and strategies for dealing with problems to their children. Symptoms (or anticipation of symptoms) may interfere with the father seeing and meeting the child's needs, and the father may distance himself from the child in order to protect the child from his anger or to protect himself from fears and intrusive thoughts that their children may catalyze, causing estrangement, emotional difficulties and other consequences. Gavlovski and Lyons (2004) survey of the literature found that a father's unexplained PTSD symptoms contributed to children's sense of the family atmosphere of fear, caution, and guilt.
Benotsch et al. (2000) hypotheses that early levels of avoidance and emotional distress drive family members away and long term PTSD are associated with low family cohesion and low levels of social support was supported in this study. All the peacekeepers in this study recognized the need for a full emotional life in order to create and maintain family and social relationships. King et al. (2006) found that while veterans without PTSD perceived their social support to rise over time, veterans with PTSD perceived that support to decline over time. Their study found that PTSD symptom severity was related to withdrawal of social support and that individuals with PTSD are likely to erode their social and familial support networks. Returning partners may not fill the role that they left, leaving confusion amongst other family members, particularly children, about the new family dynamic (Dekel et al., 2005). Shifting family roles is a theme common to this literature. It's been found the emotional numbing and the severity of PTSD effects veteran's ability to fill a parenting role (Samper et al., 2004) and spousal role (Dekel et al., 2005; Riggs et al., 1998). The inability of a returning veteran to fill his previous roles is likely to create stress within the family unit, which may result in withdrawal of emotional support for the veteran, compounding his symptoms and therefore making it more difficult for him to fill the desired role. These findings were supported in the present study as the peacekeepers expressed difficulty with fulfilling their spousal and parental roles upon their return home.

In this study, emotional numbing created barriers between the veterans and their relationships with their families and therefore, created a struggle with healing from trauma. The veterans in this study found it difficult to heal from PTSD and resume daily life without the support of their friends and family, but as they continued to distance themselves and behave in socially inappropriate ways, family and friends withdrew their support. During the withdrawal of this support, veterans in our study indicated feeling isolated and rejected. While they recognized the need for the support of their family and friends, most did not understand how their own behaviour was causing this withdrawal.

\section{Implications and recommendations}

Although there is a significant amount of literature on veterans with PTSD, there is a limited amount of literature on the impact of PTSD on family relationships and the impact of these relationships on veterans healing from trauma. Therefore, further studies are needed to understand the impact of PTSD on families and the ways in which the impact on families affect the veterans' ability to heal from trauma. Although this study is limited to the impact of PTSD on family relationships and the impact of these relationships on healing from trauma for these particular peacekeepers, it is also likely to be reflective of other military personnel who are suffering from trauma. Therefore, based on the findings from these particular peacekeepers, the following are implications and recommendations for future consideration. 
The impact of PTSD on family relationships in particular emotional numbing and anger should be heeded. The effective treatment for PTSD should include friends and family members, but should focus on helping sufferers improve interpersonal skills and work with their existing social supports as well as forming new ones, such as peer support groups. These recommendations for treatment have been supported by clinicians working with this population (Catherall, 1997; Lyons and Root, 2001; Peebles-Kleiger and Kleiger, 1994).

Studies are needed to test the efficacy of various treatment approaches in order to provide the best care for veterans. One suggestion for a treatment approach for veterans involves Dialectical Behaviour Therapy (DBT) (Linehan, 1993). DBT, an adaptation of Cognitive Behaviour Therapy, has been found to be effective in patients with borderline personality disorder, Complex Post-traumatic Stress Disorder (CPTSD) and eating disorders. Many of these patients have an underlying history of trauma including physical, sexual, emotional and psychological abuse (Koerner and Linehan, 2000). Patients receiving DBT have reported feeling less depressed, less hopeless and less angry (Koerner and Linehan, 2000; Safer et al., 2007). DBT involves the development of emotional regulation skills, mindfulness, distress tolerance and interpersonal effectiveness (Linehan, 1993) which may be beneficial for veterans as well as their families living with PTSD. However, research is needed to test the efficacy of DBT with this population and their families.

Trauma profoundly affects the body and many symptoms of traumatized individuals are somatically based. Mind-body therapies often reduces PTSD symptoms, and the ability to track body sensation helps clients experience present reality rather than reacting as if the trauma were still occurring (Ogden et al., 2006). According to Ogden et al. (2006), it takes a body to heal a trauma which requires mind/body therapies that combine cognitive approaches with somatically based interventions such as tracking bodily sensations in order "to unify both the mental and physical components of trauma (to overcome) post-traumatic defeat" (pp. 188-189). However, further empirical research is needed to test the efficacy of mind/ body therapies.

\section{Conclusion}

This study extends our understanding of the impact of PTSD on family relationships and the impact of these relationships on healing from trauma. As in previous studies, emotional numbing and anger negatively affects relationships with spouses, children, extended family members and the family unit as a whole. In addition, it was found that the veteran's emotional withdrawal from family support created a struggle with healing from trauma. In light of the present deployments of multinational troops to countries worldwide, it is vital that nurses, other health care professionals and policy makers understand the impact of PTSD on family relationships and the impact of these relationships on healing from trauma in order to provide the best treatment approaches to veterans upon their return home.
Conflict of interest. None declared.

Funding. This study was funded by an internal grant from the Social Science and Humanities Research Council (SSHRC), University of Western Ontario.

Ethical approval. Ethical approval was given by the following: University of Alberta, Health Research Ethics Board File \#B130705; University of Western Ontario, Office of Research Ethics-Review \#11716E.

\section{References}

American Psychiatric Association, 2000. Diagnostic and Statistical Manual of Mental Disorders, 4th ed. American Psychiatric Association, Washington.

Beere, D.B., 1995. Dissociative reactions and characteristics of the trauma: preliminary tests of perceptual theory of dissociation. Dissociation 8 (3), 175-2002.

Benotsch, E.G., Brailey, K., Vasterlin, J.J., Uddo, M., Constans, J., Sutker, P., 2000. War zone stress, personal and environmental resources, and PTSD symptoms in Gulf War veterans: a longitudinal perspective. Journal of Abnormal Psychology 109 (2), 205-213.

Bollnow, O.F., 1961. Lived space. Philosophy Today 5, 31-39.

Bolton, E.E., Litz, B.T., Glenn, D.M., Orsillo, S., Roember, L., 2002. The impact of homecoming reception on the adaptation of peacekeepers following deployment. Military Psychology 14 (3), 241-251.

Catherall, D.R., 1997. Family treatment when a member has PTSD. National Center for PTSD Clinical Quarterly 7 (2), 19-21.

Crossley, N., 1995. Body techniques, agency and inter-corporality. Sociology 1 (1), 133-150.

Curran, E.C., 1997. Fathers with war-related PTSD. National Center for PTSD Clinical Quarterly 7 (2), 30-33.

Dallaire, R., 2003. Shake Hands with the Devil: The Failure of Humanity in Rwanda. Random House, Canada.

Dekel, R., Goldblatt, H., Keidar, M., Solomon, Z., Polliack, M., 2005. Being a wife of a veteran with posttraumatic stress disorder. Family Relations 54 (1), 24-36.

English, A., 1999. Creating a System for Dealing with Operational Stress in the Canadian Forces: Board of Inquiry-Croatia. Government of Canada Publication, Ottawa, pp. 5-6.

Frederikson, L.G., Chamerlain, K., Long, N., 1996. Unacknowledged casualties of the Vietnam War: Experiences of partners of New Zealand veterans. Qualitative Health Research 6 (1), 49-70.

Gavlovski, T., Lyons, J.A., 2004. Psychological sequellae of combat violence: a review of the impact of PTSD on the veteran's family and possible interventions. Aggression and Violent Behaviour 9, 477-501.

Heaton, J., 2004. Reworking Qualitative Data. Sage Publications, London.

Kessler, R.C., 2000. Posttraumatic stress disorder: the burden to the individual and society. Journal of Clinical Psychiatry 61 (5), 4-12.

King, D., Taft, C., King, L., Hammond, C., Stone, E., 2006. Directionality of the association between social support and posttraumatic stress disorder: a longitudinal investigation. Journal of Applied Social Psychology 36 (12), 2980-2992.

Koenen, K., Stellman, J., Stellman, S., Sommer, J., 2003. Risk factors for course of posttraumatic stress disorder among Vietnam veterans: a 14 year follow-up of American Legionnaires. Journal of Consulting and Clinical Psychology 71 (6), 980-986.

Koerner, K., Linehan, M., 2000. Research on dialectical behavior therapy for patients with border line personality disorder. Psychiatry clinics of North America 23 (1), 151-167.

Levine, P., 1997. Walking the Tiger: Healing Trauma. North Atlantic Books, New York.

Linehan, M., 1993. Cognitive Behavioral Treatment for Patients with Borderline Personality Disorder. Guilford Press, New York.

Lyons, J.A., Root, L.P., 2001. Family members of the PTSD veteran: treatment needs and barriers. National Center for PTSD Clinical Quarterly $10(3), 48-52$

Manguno-Mire, G., Sautter, F., Lyons, J., Myers, L., Perry, D., Sherman, M., Glynn, S., Sullivan, G.، 2007. Psychological distress and burden among female partners of combat victims with PTSD. Journal of Nervous and Mental Disease 195 (2), 144-151.

Merleau-Ponty, M., 1962. Phenomenology of Perception Smith, M. (Trans.)Routledge, New York.

Ogden, P., Minton, K., Pain, C., 2006. Trauma and the Body: A Sensorimotor Approach to Psychotherapy. W.W. Norton, New York. 
Passey, G., Crockett, D., 1999. Psychological Consequences of Canadian UN Peacekeeping. Government of Canada Publication, Ottawa.

Peebles-Kleiger, M.J., Kleiger, J.H., 1994. Re-integration stress for desert storm families: wartime deployments and family trauma. Journal of Traumatic Stress 7 (2), 173-194.

Ray, S.L., in press. The experience of contemporary peacekeepers healing from trauma. Nursing Inquiry.

Repetti, R.L., Taylor, S.E., Seeman, T.S., 2002. Risky families: family social environments and the mental and physical health of the offspring. Psychological Bulletin 128 (2), 330-366.

Riggs, D.S., Byrne, C.A., Weathers, F.W., Litz, B.T., 1998. The quality of the intimate relationships of male Vietnam veterans: problems associated with posttraumatic stress disorder. Journal of Traumatic Stress 11 (1), 87-101.

Rosenheck, R., Thomson, J., 1986. Detoxification of Vietnam War trauma: a combined family-individual approach. Family Process $25,559-570$

Ruscio, A.M., Weathers, F., King, L.A., King, D.W., 2002. Male war-zone veterans' perceived relationships with their children: the importance of emotional numbing. Journal of Traumatic Stress 15 (5), 351-357.

Safer, D., Couturier, J., Lock, J., 2007. Dialectical behaviour therapy modified for adolescent eating disorder, Cognitive Behavioural Therapy 14 (2), 157-167

Samper, R., Taft, C., King, D., King, L., 2004. Posttraumatic stress disorder symptoms and parenting satisfaction among a national sample of male Vietnam veterans. Journal of Traumatic Stress 17 (4), 311-315.

Stolorow, R.D., Atwood, G.E., Orange, D.M., 2002. Worlds of Experience: Interweaving Philosophical and Clinical Dimensions in Psychoanalysis. Basic Books, New York.
Stolorow, R.D., 2003. Trauma and temporality. Psychoanalytic Psychology 20 (1), 158-161.

Szabo, V., Strang, V.R., 1997. Secondary analysis of qualitative data: methods of clinical inquiry. Advances in Nursing Science 20 (2) 66-74.

Taft, C.T., Pless, A.P., Stalans, L.J., Koenen, K.C., King, L.A., King, D.W., 2005. Risk factors for partner violence among a national sample of combat veterans. Journal of Consulting and Clinical Psychology 73 (1), 151-159.

Taft, C.T., Street, A.E., Marshall, A.D., Dowdall, D.J., Riggs, D.S., 2007. Posttraumatic stress disorder, anger, and partner abuse among Vietnam combat veterans. Journal of Family Psychology 21 (2), 270-277.

Thorne, S., 1998. Pearls, pith and provocation: ethical and representational issues in secondary analysis. Qualitative Health Research 8 (4) $547-555$.

Timms, R., Connors, P., 1992. Embodying Healing: Integrating Bodywork and Psychotherapy in Recovery from Childhood Sexual Abuse. The Safer Society Press, Orwell, VT.

Van Manen, M., 1998a. Researching Lived Experience, 3rd ed. The Althouse Press, London.

Wilde, M.H., 1999. Why embodiment now? Advances in Nursing Science 22 (2), 25-38.

Williams, C.M., 1980. The "veteran system" with a focus on women partners: theoretical considerations, problems, and treatment strategies. In: Williams, T. (Ed.), Post-traumatic Stress Disorders of the Vietnam Veteran: Observations and Recommendations for the Psychological Treatment of the Veteran and his Family. Disabled American Veterans, Cincinnati, pp. 73-121.

Young, L., 1992. Sexual abuse and the problem of embodiment. Child Abuse \& Neglect 16, 89-100. 